\title{
The risks of cancer development in systemic lupus erythematosus (SLE) patients: a systematic review and meta- analysis
}

\author{
Lebin Song ${ }^{1+}$, Yi Wang ${ }^{2+}$, Jiayi Zhang ${ }^{2+}$, Ninghong Song ${ }^{2}$, Xiaoyun X ${ }^{1 *}$ (D) and Yan Lu ${ }^{1 *}$
}

\begin{abstract}
Background: Although accumulating data have suggested the development of cancer in systemic lupus erythematosus (SLE) patients, these results remain inconsistent. To examine such a putative association, this analysis reports the association between SLE and the risks of 24 cancer types.

Methods: Online databases PubMed, EMBASE, and Web of Science were searched comprehensively for eligible studies, published up to 15 May 2018. Pooled standardized incidence rates (SIRs) with 95\% confidence intervals (Cls) were utilized to reveal their associations.

Results: A total of 24 eligible studies were ultimately enrolled. Our results indicated that SLE was associated with increased risk of overall cancers, cancer risk in both genders, non-Hodgkin's lymphoma, Hodgkin's lymphoma, leukemia, multiple myeloma, cervix, vagina/vulva, renal, bladder, esophagus, gastric, hepatobiliary, lung, oropharynx, larynx, non-melanoma skin, and thyroid cancers. Additionally, SLE could reduce the risk of prostate cancer and cutaneous melanoma; however, it was not significantly associated with breast, uterus, ovarian, pancreatic, colorectal, or brain cancers.

Conclusions: Our results shed light SLE being correlated with increased risk for 16 involved cancers and decreased risk for prostate cancer and cutaneous melanoma. This comprehensive meta-analysis provides epidemiological evidence supporting the associations between SLE and cancer risk. This evidence could be utilized to drive public policies and to help guide personalized medicine to better manage SLE and reduce associated cancer morbidity and mortality.
\end{abstract}

Keywords: Systemic lupus erythematosus, Cancer, Meta-analysis

\section{Background}

Systemic lupus erythematosus (SLE), defined as a complex and chronic inflammatory autoimmune disease, is characterized by the production of autoantibodies, complement activation, and immune complex deposition, which can be directed against almost any organ system in a heterogeneous array of clinical manifestations [1]. SLE predominantly occurs in young and middle-aged

\footnotetext{
* Correspondence: xiaoyunhl@126.com; luyan6289@163.com

†Lebin Song, Yi Wang and Jiayi Zhang contributed equally to this work.

${ }^{1}$ Department of Dermatology, The First Affiliated Hospital of Nanjing Medical

University, No. 300 Guangzhou Road, Nanjing 210029, China

Full list of author information is available at the end of the article
}

people with a female to male ratio of 10:1 [2], and the kidneys and the skin are the most intensively affected organs $[3,4]$. Regarding the incidence and prevalence of SLE, the highest estimates of disease are in North America and in people of African ethnicity [5]. Major causes of morbidity and mortality in SLE patients include infection, cancer, renal failure, myocardial infarction, and central nervous system disease [6-9]. Due to early meticulous diagnosis and the progress of treatment, survival rates for SLE patients have increased remarkably in recent decades. Despite their increased life expectancy, these patients still have two- to five-times the risk of

(c) The Author(s). 2018 Open Access This article is distributed under the terms of the Creative Commons Attribution 4.0 International License (http://creativecommons.org/licenses/by/4.0/), which permits unrestricted use, distribution, and 
Table 1 Main characteristics of individual studies included in this meta-analysis

\begin{tabular}{|c|c|c|c|c|c|c|c|}
\hline First author & Year & Data origin & $\begin{array}{l}\text { Calendar } \\
\text { period }\end{array}$ & $\begin{array}{l}\text { No.of SLE patients } \\
\text { (gender) }\end{array}$ & $\begin{array}{l}\text { SLE } \\
\text { diagnosis }\end{array}$ & Follow-up & $\begin{array}{l}\text { NOS } \\
\text { scores }\end{array}$ \\
\hline Tallbacka [14] & 2018 & $\begin{array}{l}\text { The Helsinki University } \\
\text { Central Hospital }\end{array}$ & $1967-1987$ & $\begin{array}{l}205 \text { (182 females and } \\
23 \text { males) }\end{array}$ & $\begin{array}{l}\text { ARA } \\
\text { criteria }\end{array}$ & 25.7 years & 7 \\
\hline Yun [11] & 2017 & $\begin{array}{l}\text { National Health Insurance } \\
\text { System database }\end{array}$ & 2009-2013 & $\begin{array}{l}17,495 \text { ( } 15,826 \text { females and } \\
1669 \text { males) }\end{array}$ & NA & NA & 8 \\
\hline Azrielant [13] & 2017 & Clalit Health Services & 2013 & 5018 (all males) & NA & NA & 6 \\
\hline Yu [21] & 2016 & $\begin{array}{l}\text { The Taiwan National } \\
\text { Health Insurance Research } \\
\text { Database (NHIRD) }\end{array}$ & 1997-2010 & $\begin{array}{l}15,623 \text { ( } 13,693 \text { females and } \\
1930 \text { males) }\end{array}$ & $\begin{array}{l}\mathrm{ACR} \\
\text { criteria }\end{array}$ & $\begin{array}{l}124,832.45 \text { person- } \\
\text { years }\end{array}$ & 8 \\
\hline Waseem [22] & 2015 & 2006 Medicare claims data & 2006 & 18,423 (all females) & NA & NA & 8 \\
\hline Bernatsky [24] & 2013 & Multi-center & 1958-2009 & 16,409 (90\% females) & $\begin{array}{l}\mathrm{ACR} \\
\text { criteria }\end{array}$ & 7.4 years $/ 121,283$ years & 8 \\
\hline Dey [23] & 2013 & $\begin{array}{l}\text { The University College } \\
\text { London Hospitals Lupus Clinic }\end{array}$ & 1978-2010 & 595 & $\begin{array}{l}\text { ACR } \\
\text { criteria }\end{array}$ & $\begin{array}{l}14.7 \text { years } / 8910.51 \\
\text { person-years }\end{array}$ & 6 \\
\hline Hemminki [25] & 2012 & $\begin{array}{l}\text { Swedish Hospital Discharge } \\
\text { Register }\end{array}$ & 1964-1986 & 7624 & NA & $\begin{array}{l}11.9 \text { years } / 86,640 \\
\text { person-years }\end{array}$ & 8 \\
\hline Dreyer [26] & 2011 & Central Population Register & $1951-2006$ & $\begin{array}{l}576 \text { ( } 508 \text { females and } \\
68 \text { males) }\end{array}$ & $\begin{array}{l}\text { ACR } \\
\text { criteria }\end{array}$ & 13.2 years/7803 years & 7 \\
\hline Kang [27] & 2010 & Kangnam St. Mary's Hospital & 1997-2007 & 914 (all females) & $\begin{array}{l}\text { ACR } \\
\text { criteria }\end{array}$ & 5716 person-years & 8 \\
\hline Chen [15] & 2010 & $\begin{array}{l}\text { National Health Insurance } \\
\text { Research Database }\end{array}$ & 1996-2007 & $\begin{array}{l}11,763 \text { (10,394 females and } \\
1369 \text { males) }\end{array}$ & $\begin{array}{l}\text { ARA } \\
\text { criteria }\end{array}$ & 6.1 years & 5 \\
\hline Gadalla [28] & 2009 & $\begin{array}{l}\text { Surveillance, Epidemiology } \\
\text { and End Results-Medicare-linked } \\
\text { database }\end{array}$ & 1993-2002 & 340 & NA & NA & 8 \\
\hline Parikh-Patel [29] & 2008 & $\begin{array}{l}\text { Statewide patient discharge } \\
\text { data }\end{array}$ & 1991-2002 & $\begin{array}{l}30,478 \text { ( } 27,133 \text { females and } \\
3345 \text { males) }\end{array}$ & NA & 5.1 years/157,969 years & 6 \\
\hline Tunde [30] & 2007 & A single center & 1970-2004 & $\begin{array}{l}860 \text { (771 female and } \\
89 \text { male) }\end{array}$ & $\begin{array}{l}\text { ACR } \\
\text { criteria }\end{array}$ & 13.4 years & 8 \\
\hline Bernatsky [31] & 2005 & Multi-center & 1958-2000 & $\begin{array}{l}9547 \text { ( } 8607 \text { females and } 940 \\
\text { males) }\end{array}$ & $\begin{array}{l}\text { ACR } \\
\text { criteria }\end{array}$ & $\begin{array}{l}8.0 \text { years } / 76,948 \\
\text { person-years }\end{array}$ & 7 \\
\hline Ragnarsson [32] & 2003 & Icelandic SLE database & 1957-2001 & $\begin{array}{l}238 \text { ( } 213 \text { females and } \\
25 \text { males) }\end{array}$ & $\begin{array}{l}\text { ARA } \\
\text { criteria }\end{array}$ & 12.8 years/ 2774 years & 8 \\
\hline Bjornadal [33] & 2002 & $\begin{array}{l}\text { Swedish National Board } \\
\text { of Health and Welfare } \\
\text { recorded data }\end{array}$ & 1964-1995 & $\begin{array}{l}5715 \text { ( } 4201 \text { females and } 1514 \\
\text { males) }\end{array}$ & NA & 50,246 person-years & 8 \\
\hline Cibere [34] & 2001 & $\begin{array}{l}\text { University-based Rheumatic } \\
\text { Disease UniT }\end{array}$ & 1975-1994 & 297 (84\% females) & $\begin{array}{l}\text { ACR } \\
\text { criteria }\end{array}$ & 12 years & 7 \\
\hline Sultan [35] & 2000 & $\begin{array}{l}\text { Board of Health and } \\
\text { Welfare recorded data }\end{array}$ & 1978-1999 & 276 (93.5\% females) & $\begin{array}{l}\text { ARA } \\
\text { criteria }\end{array}$ & 4.8 years $/ 1695$ years & 7 \\
\hline $\begin{array}{l}\text { Ramsey- } \\
\text { Goldman [36] }\end{array}$ & 1998 & NA & NA & 616 & NA & NA & 5 \\
\hline Mellemkjaer [37] & 1997 & $\begin{array}{l}\text { Nationwide Danish Hospital } \\
\text { Discharge Register }\end{array}$ & 1977-1989 & $\begin{array}{l}1585 \text { (1308 females and } 277 \\
\text { males) }\end{array}$ & $\begin{array}{l}\text { ACR } \\
\text { criteria }\end{array}$ & $\begin{array}{l}6.8 \text { years } / 10,807 \\
\text { personyears }\end{array}$ & 6 \\
\hline Abu-Shakra [38] & 1996 & $\begin{array}{l}\text { The University of Toronto } \\
\text { Lupus Clinic Database }\end{array}$ & NA & $\begin{array}{l}724 \text { ( } 627 \text { females and } \\
97 \text { males) }\end{array}$ & $\begin{array}{l}\text { ACR } \\
\text { criteria }\end{array}$ & 7233 person-years & 6 \\
\hline Sweeney [39] & 1995 & NA & NA & 219 & NA & NA & 5 \\
\hline Pettersson [40] & 1992 & $\begin{array}{l}\text { Fourth Department of } \\
\text { Medicine, Helsinki University } \\
\text { Central Hospital }\end{array}$ & 1967-1987 & $\begin{array}{l}205 \text { ( } 182 \text { females and } \\
23 \text { males) }\end{array}$ & $\begin{array}{l}\text { ARA } \\
\text { criteria }\end{array}$ & 2340 person-years & 5 \\
\hline
\end{tabular}

SLE systemic lupus erythematosus, ACR criteria American College of Rheumatology criteria, ARA criteria American Rheumatism Association criteria, NA not available. 
death compared with the general population, not only for all-cause mortality but also for mortality from cancer [10]. As a result, more attention should be paid to the risks of cancer development in patients with SLE.

Until now, a growing amount of research has attempted to reveal the incidence of cancers in SLE patients, and several studies have successfully demonstrated that SLE is significantly associated with increased risks of thyroid cancer [11], cervix cancer [12], and hematologic cancer [13]. With more than 25 years of follow-up, Tallbacka et al. confirmed that patients with SLE had an increased risk of cancer, particularly non-Hodgkin's lymphoma and kidney cancer [14]. Moreover, Chen et al. reported a decreased risk of prostate cancer and bladder cancer in a cohort of 11,763 lupus patients in Taiwan [15]. There are also several studies suggesting that no direct associations exist between particular cancers and SLE. For instance, Rezaieyazdi et al. suggested that SLE was not dramatically related with the risk of breast cancer [16]. However, their results were

Table 2 Meta-analysis results for included studies of the relationship between SLE and risks of various cancers

\begin{tabular}{|c|c|c|c|c|c|c|c|}
\hline Variables & NO.of studies & Effects model & $\operatorname{SIR}(95 \% \mathrm{Cl})$ & I-squared (\%) & $P$ values & Relationship & Publication bias \\
\hline \multicolumn{8}{|l|}{ Overall characteristics } \\
\hline Overall cancers & 10 & Random & $1.28(1.16-1.42)$ & $71.9 \%$ & $<0.001$ & Increased risks & None \\
\hline Female & 4 & Random & $1.49(1.15-1.93)$ & $72.7 \%$ & 0.012 & Increased risks & None \\
\hline Male & 5 & Random & $1.59(1.18-2.14)$ & $78.8 \%$ & 0.001 & Increased risks & None \\
\hline \multicolumn{8}{|c|}{ SLE associated with Lymphatic and haematopoietic cancers } \\
\hline Non-Hodgkin's lymphoma & 11 & Random & $4.93(3.81-6.36)$ & $55.2 \%$ & 0.014 & Increased risks & None \\
\hline Hodgkin's lymphoma & 8 & Fixed & $2.60(2.14-3.17)$ & $0.0 \%$ & 0.660 & Increased risks & Existence \\
\hline Leukemia & 10 & Fixed & $2.01(1.64-2.47)$ & $24.3 \%$ & 0.220 & Increased risks & None \\
\hline Multiple myeloma & 4 & Fixed & $1.48(1.02-2.14)$ & $0.0 \%$ & 0.744 & Increased risks & None \\
\hline \multicolumn{8}{|c|}{ SLE associated with Reproductive cancers } \\
\hline Breast cancer & 19 & Random & $0.89(0.77-1.04)$ & $70.1 \%$ & $<0.001$ & No association & None \\
\hline Uterus cancer & 6 & Random & $0.70(0.46-1.07)$ & $58.3 \%$ & 0.035 & No association & None \\
\hline Cervix cancer & 11 & Fixed & $1.56(1.29-1.88)$ & $4.1 \%$ & 0.404 & Increased risks & None \\
\hline Ovarian cancer & 11 & Fixed & $0.92(0.74-1.33)$ & $14.2 \%$ & 0.309 & No association & None \\
\hline Vagina/vulva cancer & 8 & Fixed & $3.48(2.69-4.50)$ & $0.0 \%$ & 0.813 & Increased risks & None \\
\hline \multicolumn{8}{|c|}{ SLE associated with Urinary cancers } \\
\hline Prostate cancer & 11 & Fixed & $0.78(0.70-0.88)$ & $14.4 \%$ & 0.307 & Decreased risks & None \\
\hline Renal cancer & 6 & Random & $2.10(1.11-3.96)$ & $65.2 \%$ & 0.013 & Increased risks & None \\
\hline Bladder cancer & 10 & Random & $1.86(1.16-2.99)$ & $75.1 \%$ & $<0.001$ & Increased risks & None \\
\hline \multicolumn{8}{|c|}{ SLE associated with Digestive cancers } \\
\hline Esophagus cancer & 5 & Fixed & $1.64(1.43-1.87)$ & $0.0 \%$ & 0.725 & Increased risks & None \\
\hline Gastric cancer & 8 & Fixed & $1.31(1.04-1.63)$ & $0.0 \%$ & 0.789 & Increased risks & None \\
\hline Hepatobiliary cancer & 11 & Random & $2.37(1.67-3.38)$ & $50.4 \%$ & 0.028 & Increased risks & None \\
\hline Pancreatic cancer & 9 & Fixed & $1.24(0.97-1.60)$ & $6.2 \%$ & 0.384 & No association & None \\
\hline Colorectal cancer & 13 & Fixed & $0.97(0.85-1.09)$ & $0.0 \%$ & 0.907 & No association & None \\
\hline \multicolumn{8}{|c|}{ SLE associated with Respiratory cancers } \\
\hline Lung cancer & 15 & Random & $1.62(1.40-1.87)$ & $46.0 \%$ & 0.026 & Increased risks & None \\
\hline Oropharynx cancer & 5 & Fixed & $1.52(1.00-2.30)$ & $0.0 \%$ & 0.721 & Increased risks & None \\
\hline Larynx cancer & 4 & Fixed & $2.90(1.82-4.62)$ & $15.3 \%$ & 0.315 & Increased risks & None \\
\hline \multicolumn{8}{|l|}{ SLE associated with Other cancers } \\
\hline Cutaneous melanoma & 6 & Fixed & $0.72(0.56-0.93)$ & $0.0 \%$ & 0.424 & Decreased risks & None \\
\hline Non-melanoma skin cancer & 4 & Fixed & $1.41(1.07-1.87)$ & $28.7 \%$ & 0.240 & Increased risks & None \\
\hline Brain cancer & 6 & Fixed & $1.08(0.64-1.81)$ & $0.0 \%$ & 0.765 & No association & None \\
\hline Thyroid cancer & 7 & Fixed & $1.80(1.46-2.23)$ & $0.0 \%$ & 0.795 & Increased risks & None \\
\hline
\end{tabular}


not comprehensive, and some outcomes remained inconsistent. Hence, this meta-analysis was conducted to comprehensively shed light on the relationship between SLE and various cancers.

Here, 24 human malignant neoplasms were systematically divided into six systemic groups (lymphatic and hematopoietic cancers, reproductive cancers, urinary cancers, digestive cancers, respiratory cancers, and others) which were evaluated respectively. The outcomes from each could be utilized as a reference for future clinical management.

\section{Materials and methods Search strategy}

To investigate the potential relationship between SLE and various cancers, relevant articles were comprehensively and systematically identified from the online databases PubMed, EMBASE, and Web of Science, published up to 15 May 2018. Pooled standardized incidence rates (SIRs) with $95 \%$ confidence intervals (CIs) were utilized to clarify their correlations. The search strategy mainly consisted of the following keywords in combination with Medical Subject Headings (MeSH) terms and text words: ("Systemic Lupus Erythematosus" or "Lupus Erythematosus Disseminatus" or "Libman-Sacks Disease" or "Libman Sacks Disease") and ("Neoplasia" or "Neoplasias" or "Neoplasm" or "Tumors" or "Tumor" or "Cancer" or "Cancers" or "Malignant Neoplasms" or "Malignant Neoplasm" or "Malignancy" or "Malignancies"). The subsequent meta-analysis was strictly performed according to the Preferred Reporting Items for Systematic Reviews and Meta-Analyses (PRISMA) statement [17].

\section{Inclusion/exclusion criteria}

Relevant articles finally enrolled in this meta-analysis met the following criteria: 1) language was restricted to English publications; 2) patients were diagnosed with SLE; 3) focused on the incidence of cancers in SLE patients; and 4) sufficient data provided by means of SIRs with 95\% CIs. The major exclusion criteria were: 1) non-English articles; 2) duplicates or reviews or letters or case reports or comments or editorials; 3) simple description without comparison; 4) absence of key information; and 5) unrelated to SLE or cancers.

\section{Data extraction and quality assessment}

The whole selection process and eligible articles were independently determined by two blinded reviewers (LS and YW) based on the inclusion and exclusion criteria. Disagreements were addressed by consultation with a third reviewer (JZ). The following information was extracted from enrolled articles: 1) first author's name; 2) year of publication; 3) data origin; 4) calendar period; 5) number of patients (along with gender); 6) SLE diagnosis; 7) follow-up time (years); 8) the Newcastle-Ottawa Scale (NOS) scores; 9) observed/expected events; and 10) SIRs with 95\% CIs. Methodological quality assessment of each eligible article was assessed with the NOS (http://www.ohri.ca/programs/clinical_epidemiology/oxford.htm), one of the most useful scales for evaluating the quality of nonrandomized studies [18]. The NOS scale utilizes a star rating system (with scores ranging from 0 to 9 ) to evaluate the quality of each study. Studies awarded six or more stars are regarded as high quality.

\section{Statistical analysis}

The association between SLE and various cancers was analyzed based on available data, and the pooled SIRs with 95\% CIs were utilized to evaluate its efficacy. Heterogeneity was assessed by means of the Chi-square test and $I^{2}$ test. If significant heterogeneity $(P<0.10$ or $I^{2}>50 \%$ ) existed, the random-effects model (the DerSimonian-Laird method) was applied. Otherwise, the fixed-effects model (the Mantel-Haenszel method) was utilized [19]. Moreover, the stability and reliability of the results were determined by sensitivity analysis by deleting one study at a time to reflect the influence of the individual outcomes on the overall outcome. Potential publication bias was accessed by Begg's funnel plot and Egger's linear regression test. A $P$ value $<0.05$ indicated the existence of publication bias [20]. In addition, all the $P$ values were adopted by a two-sided test and $P$ $<0.05$ was considered to be statistically significant. All statistical data were compiled by Stata software (version 12.0; StataCorp LP, College Station, TX, USA) and Microsoft Excel (V.2007; Microsoft Corporation, Redmond, WA, USA).

\section{Results \\ Characteristics of enrolled studies}

A total of 2019 relevant articles were identified through a primary literature search using the described search strategy and inclusion/exclusion criteria. After removing duplicates, 1627 records remained. By screening the tittles and abstracts, an additional 639 records were excluded because they were review articles, letters, case-reports, comments, or editorials. Of the remaining 713 full-text articles, 689 were also removed as they were unrelated to SLE or cancers, non-English articles, they had a simple description without comparison, or an absence of key information. Finally, 24 eligible studies were enrolled in this meta-analysis [11, 13-15, 21-40] (Additional file 1: Figure S1).

The detailed characteristics of these 24 eligible studies are summarized in Table 1 and (Additional file 2: Table S1). Specifically, a total of 24 human malignant neoplasms were 
systematically divided into six systemic groups (lymphatic and hematopoietic cancers, reproductive cancers, urinary cancers, digestive cancers, respiratory cancers, and others). Lymphatic and hematopoietic cancers mainly consisted of non-Hodgkin's lymphoma, Hodgkin's lymphoma, multiple myeloma, and leukemia. Reproductive cancers included five cancers (breast cancer, uterus cancer, cervix cancer, ovarian cancer, and vagina/vulva cancer). The urinary cancer group was predominantly made up of renal cancer, prostate cancer, and bladder cancer. Esophagus cancer, gastric cancer, hepatobiliary cancer, pancreatic cancer, and colorectal cancer were involved in the digestive cancers. Lung cancer, oropharynx cancer, and larynx cancer were considered as respiratory cancers. Finally, other cancers were mainly comprised of the following four cancers (cutaneous melanoma, non-melanoma skin cancer, brain cancer, and thyroid cancer).

\section{Overall characteristics}

A total of ten studies contributed to the analysis of SLE and overall cancer incidence within the random-effects model based on the moderate heterogeneity among studies $(P<$ $0.001, I^{2}=71.9 \%$ ) (Table 2). Our results indicated that SLE was correlated with increased risk of overall cancers (pooled SIR $=1.28,95 \% \mathrm{CI}=1.16-1.42$ ) (Fig. 1a). With regard to the relationship between SLE and gender, the outcomes successfully shed light on SLE being associated with increased risks of both females and males suffering from cancers within the random-effects model (pooled SIR = 1.49, $95 \% \mathrm{CI}=1.15-1.93, P=0.012, I^{2}=72.7 \%$ and pooled $\mathrm{SIR}=1.59,95 \% \mathrm{CI}=1.18-2.14, P=0.001, I^{2}=78.8 \%$, respectively) (Fig. 1b, c).

\section{Association between SLE and lymphatic and hematopoietic cancers}

A total of 11 studies contributed to the association between SLE and non-Hodgkin's lymphoma within the random-effects model based on the moderate heterogeneity among studies $\left(P=0.014, I^{2}=55.2 \%\right)$ (Table 2). Our results showed that SLE was correlated with increased risk of non-Hodgkin's lymphoma (pooled SIR $=4.93,95 \% \mathrm{CI}=$ 3.81-6.36) (Fig. 2a). With regard to the relationship between SLE and Hodgkin's lymphoma, pooled outcomes of eight studies demonstrated that SLE could increase the risk of Hodgkin's lymphoma within the fixed-effects model (pooled SIR $=2.60,95 \% \mathrm{CI}=2.14-3.17, P=0.660, I^{2}=$ $0.0 \%$ ) (Fig. 2b). For leukemia, the analysis of 10 relevant studies showed that SLE was related to an increased risk of leukemia within the fixed-effects model (pooled SIR $=2.01$, 95\% CI $=1.64-2.47, P=0.220, I^{2}=24.3 \%$ ) (Fig. 2c). Four studies measured the relationship between multiple myeloma and SLE and were analyzed using the fixed-effects model based on no heterogeneity among studies $(P=0.744$,
$\left.I^{2}=0.0 \%\right)$. Our results also indicated that SLE could increase the risk of multiple myeloma (pooled SIR $=1.48$, 95\% CI $=1.02-2.14$ ) (Fig. 2d).

\section{Association between SLE and reproductive cancers}

A total of 19 studies contributed to the relationship between SLE and breast cancers within the random-effects model based on the moderate heterogeneity among studies $\left(P<0.001, I^{2}=70.1 \%\right)$ (Table 2$)$. Remarkably, our results failed to demonstrate any significant association



Fig. 1 Forest plots of SLE associated with overall characteristics. a Overall cancer; $\mathbf{b}$ the female group; $\mathbf{c}$ the male group 
between them (pooled SIR $=0.89,95 \% \mathrm{CI}=0.77-1.04$ ) (Fig. 3a). Similarly, uterus cancers analyzed in six studies showed that SLE was not related to such cancer incidence within the random-effects model (pooled SIR = 0.70, 95\% CI $=0.46-1.07, P=0.035, I^{2}=58.3 \%$ ) (Fig. 3b). For cervix cancers, 11 studies showed that SLE was related with increased risk of cervix cancers within the fixed-effects model (pooled SIR $=1.56,95 \% \mathrm{CI}=1.29$ $1.88, P=0.404, I^{2}=4.1 \%$ ) (Fig. 3c). With regard to ovarian cancers, 11 studies failed to display any vital association between them within the fixed-effects model (pooled SIR $=0.92,95 \% \mathrm{CI}=0.74-1.33, P=0.309, I^{2}=$ 14.2\%) (Fig. 3d). Finally, with reference to vagina/vulva cancers, the analysis of eight studies successfully revealed that SLE was correlated with increased risk of vagina/vulva cancers (pooled $\mathrm{SIR}=3.48,95 \% \mathrm{CI}=2.69$ 4.50, $P=0.813, I^{2}=0.0 \%$ ) (Fig. 3e).

\section{Association between SLE and urinary cancers}

For urinary cancers, there were 11 studies measuring the association between SLE and prostate cancer within the fixed-effects model based on the low heterogeneity among studies $\left(P=0.307, \quad I^{2}=13.4 \%\right)$ (Table 2). Our results revealed that SLE was correlated with decreased risk of prostate cancers (pooled $\mathrm{SIR}=0.78,95 \% \mathrm{CI}=0.70-0.88$ ) (Fig. 4a). For renal cancer, the analysis of six studies showed that SLE was related to an increased risk of renal cancer within the random-effects model (pooled SIR $=2.10$, 95\% CI $=1.11-3.96, \quad P=0.013, \quad I^{2}=65.2 \%$ ) (Fig. 4b). With regard to bladder cancer, a total of ten studies showed that SLE was associated with increased risk of bladder cancers within the random-effects model (pooled SIR $=1.86,95 \% \mathrm{CI}=1.16-2.99, P<0.001, I^{2}=$ 75.1\%) (Fig. 4c).

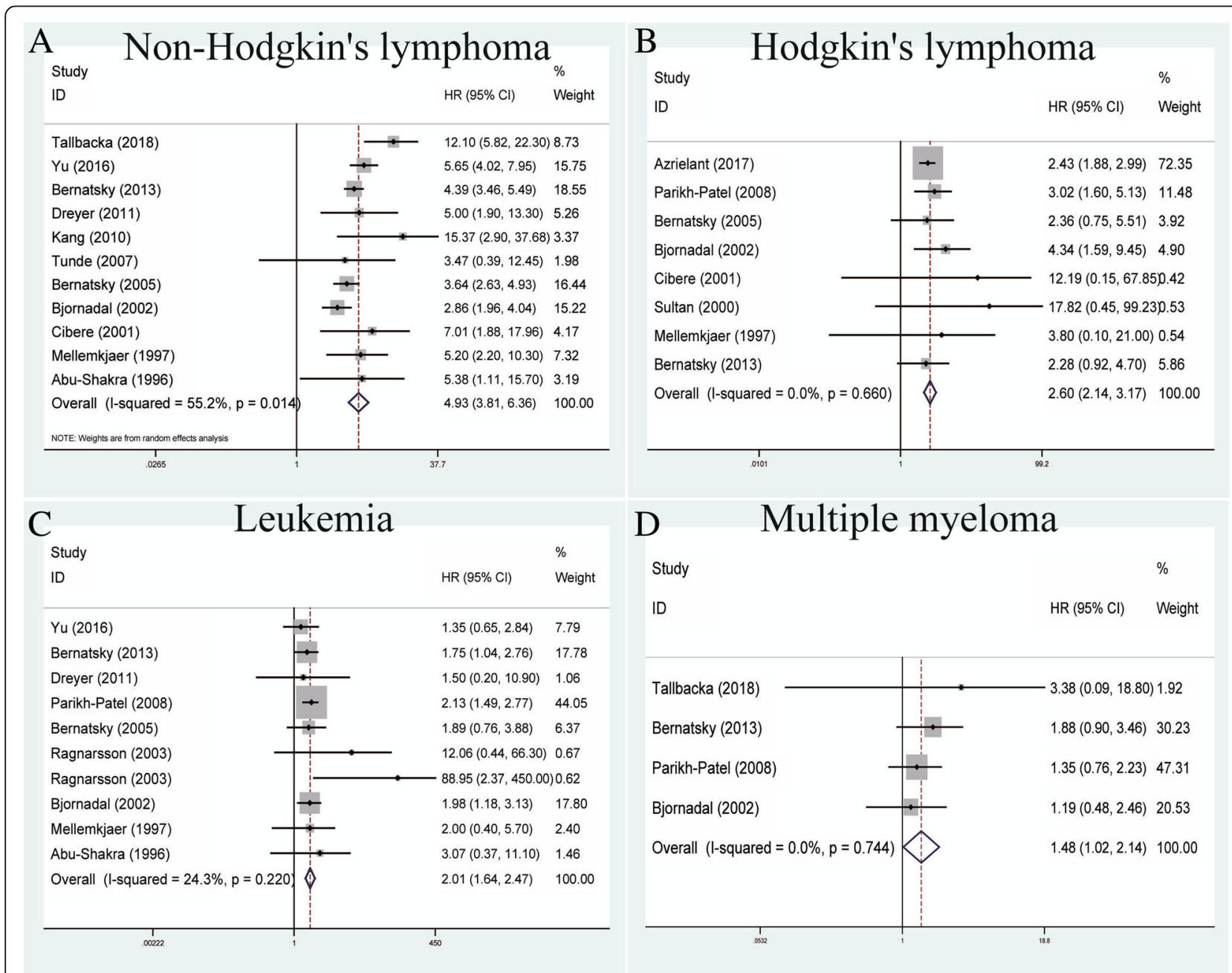

Fig. 2 Forest plots of SLE associated with lymphatic and hematopoietic cancers. a Non-Hodgkin's lymphoma; b Hodgkin's lymphoma; c leukemia; d multiple myeloma 


\section{Association between SLE and digestive cancers}

Esophageal cancer was analyzed in a total of five studies to determine its relationship with SLE using the fixed-effects model based on no heterogeneity among studies $(P=0.725$, $I^{2}=0.0 \%$ ) (Table 2). We observed that SLE could increase the risk of esophagus cancer (pooled SIR $=1.64,95 \% \mathrm{CI}=$ 1.43-1.87) (Fig. 5a). For gastric cancer, a total of eight studies showed that SLE was related to an increased risk of this cancer within the fixed-effects model (pooled SIR $\left.=1.31, \quad 95 \% \quad \mathrm{CI}=1.04-1.63, \quad P=0.789, \quad I^{2}=0.0 \%\right)$ (Fig. 5b). With regard to hepatobiliary cancers, an analysis of 11 studies showed that SLE was correlated with increased risk within the random-effects model (pooled SIR $=2.37,95 \% \mathrm{CI}=1.67-3.38, P=0.028, I^{2}=$ 50.4\%) (Fig. 5c). Finally, the associations between SLE and pancreatic cancer or colorectal cancer were found to be non-existent using the fixed-effects model (pooled SIR $=1.24,95 \% \mathrm{CI}=0.97-1.60, P=0.384, I^{2}=$ $6.2 \%$, and pooled SIR $=0.97,95 \% \mathrm{CI}=0.85-1.09, P=$ $0.907, I^{2}=0.0 \%$, respectively) (Fig. $5 \mathrm{~d}, \mathrm{e}$ ).

\section{Association between SLE and respiratory cancers}

A total of 15 studies contributed to the analysis of SLE and lung cancer within the random-effects model based on moderate heterogeneity among studies $\left(P=0.026, I^{2}=\right.$ 46.0\%) (Table 2). The outcomes showed that SLE was correlated with increased risk of lung cancers (pooled SIR = 1.62, 95\% CI $=1.40-1.87$ ) (Fig. 6a). For oropharynx cancer, a total of five studies showed that SLE was connected with an increased risk of oropharynx cancer within the fixed-effects model (pooled SIR $=1.52,95 \% \mathrm{CI}=1.00-2.30$, $P=0.721, I^{2}=0.0 \%$ ) (Fig. 6b). Finally, with regard to larynx cancer, an analysis of four studies indicated that SLE was correlated with an increased risk within the fixed-effects model (pooled SIR $=2.90,95 \% \mathrm{CI}=1.82-4.62, P=0.315$, $\left.I^{2}=15.3 \%\right)$ (Fig. 6c).

\section{Association between SLE and other cancers}

We analyzed six studies measuring the correlation between SLE and cutaneous melanoma within the fixed-effects model based on no heterogeneity among studies $\left(P=0.424, I^{2}=0.0 \%\right)$ (Table 2). Our results showed that SLE was correlated with a decreased risk of cutaneous melanoma (pooled $\mathrm{SIR}=0.72,95 \% \mathrm{CI}=$ 0.56-0.93) (Fig. 7a). For non-melanoma skin cancers, four studies indicated that SLE could increase its risk within the fixed-effects model (pooled SIR $=1.41$, 95\% $\mathrm{CI}=1.07-1.87, P=0.240, I^{2}=28.7 \%$ ) (Fig. 7b). Interestingly, brain cancer failed to demonstrate any significant association with SLE in six studies using the fixed-effects model (pooled SIR $=1.08,95 \% \mathrm{CI}=0.64$ 1.81, $P=0.765, I^{2}=0.0 \%$ ) (Fig. $7 \mathrm{c}$ ). For the association between SLE and thyroid cancer, a total of seven studies indicated that SLE was associated with an increased risk of thyroid cancer (pooled SIR $=1.80$, 95\% $\left.\mathrm{CI}=1.46-2.23, P=0.795, I^{2}=0.0 \%\right)($ Fig. $7 \mathrm{~d})$.

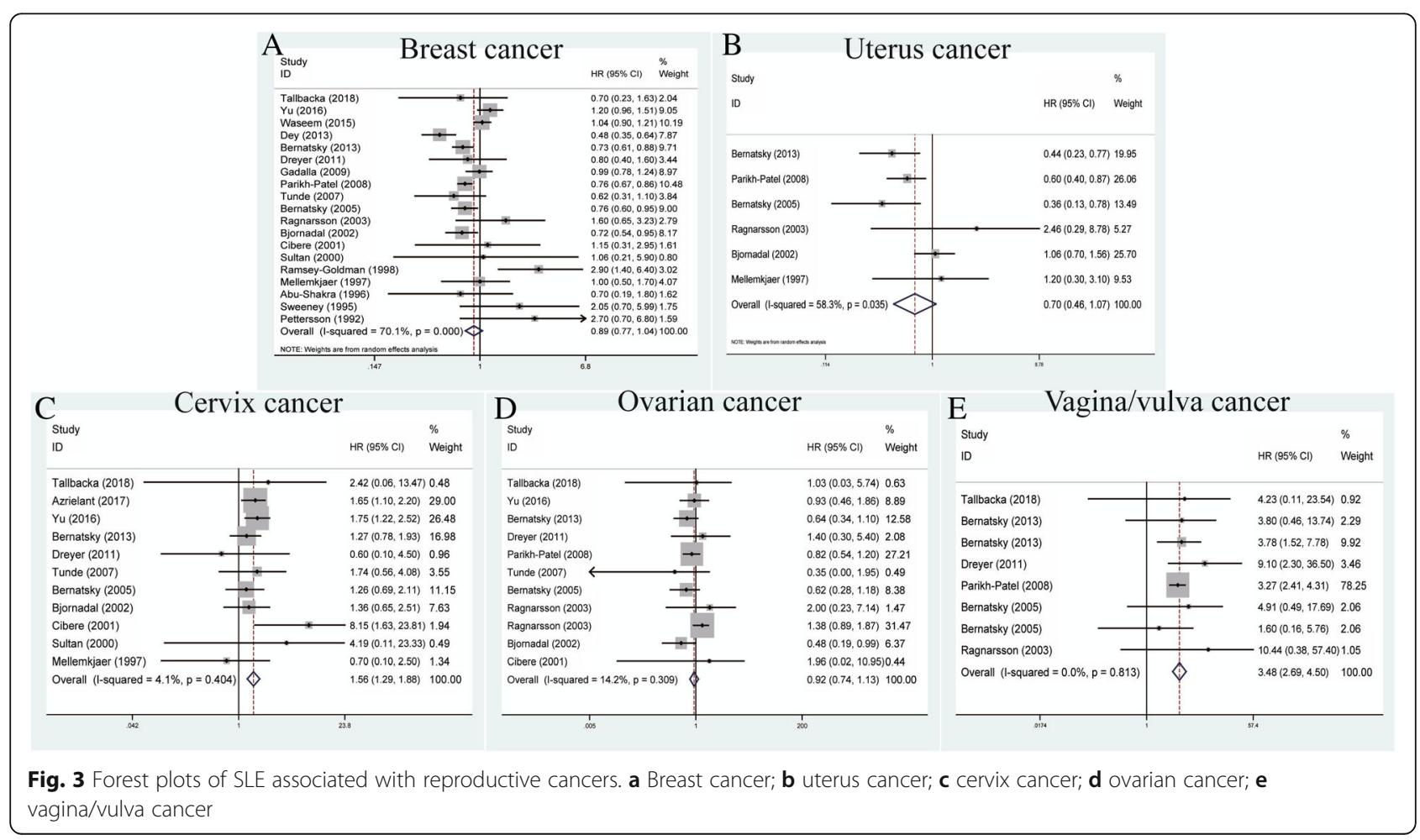




\section{Sensitivity analysis}

Sensitivity analysis was conducted by deleting a single study each time to observe the influence of the individual outcome on the overall analysis. As indicated by the results of analysis, most of the pooled SIRs with $95 \%$ CIs were not remarkably influenced by any individual study. This demonstrated the stability and reliability of our results (Additional file 3: Figure S2). However, in the analysis of male category, the study by Chen et al. [15] was found to significantly influence the estimated pooled SIR (Additional file 3: Figure S2C).

\section{Publication bias}

Potential publication bias was assessed by Begg's funnel plot and Egger's linear regression test. A $P$ value of $<0.05$ indicated the existence of publication bias (Additional file 4: Figure S3). As indicated by our results, we found that most of the $P$ values of Begg's and Egger's test were above 0.05 , indicating no significant publication bias except for those results outlined in Additional file 4: Figure S3E.

\section{Discussion}

To the best of our knowledge, this is the first and largest systematic evaluation to reveal the relationship between SLE and the development of cancer risk. The outcomes successfully shed light on SLE increasing the risks of overall cancer, cancer risk in both genders, non-Hodgkin's lymphoma, Hodgkin's lymphoma, leukemia, multiple myeloma, cervix, vagina/vulva, renal, bladder, esophagus, gastric, hepatobiliary, lung, oropharynx, larynx, non-melanoma skin, and thyroid cancers. Moreover, SLE could decrease the risks of prostate cancer and cutaneous melanoma. In addition, no significant associations were revealed between SLE and breast, uterus, ovarian, pancreatic, colorectal, or brain cancers.

In line with previous research, $\mathrm{Ni}$ et al. demonstrated that SLE patients were at increased risk of developing lung or liver cancers and a decreased risk of suffering from prostate cancer [41]. Similarly, Rezaieyazdi et al. suggested there was no direct association between SLE and risk of breast cancer incidence [16]. Inconsistent with our results, Bernatsky et al. supported a decreased risk of breast, ovarian, and endometrial cancers in SLE [42]. Huang et al. also indicated that SLE was not associated with the risk of bladder cancer [43], whereas the outcomes in our meta-analysis showed a positive association between SLE and bladder cancer. The reason for this might be that their study was composed of diminutive sample sizes without sufficient statistical power.
Moreover, our results reconfirmed the deterioration of bladder carcinoma in association with SLE treatment observed in several case series $[44,45]$.

Interestingly, our results indicated that SLE was correlated with an increased risk in overall cancers and, meanwhile, 16 of 24 analyzed cancers were positively associated with SLE; only prostate cancer and cutaneous melanoma showed a negative association with SLE. Mok and Lau suggested that a relatively lower level of testosterone, a critical risk factor for prostate cancer, might

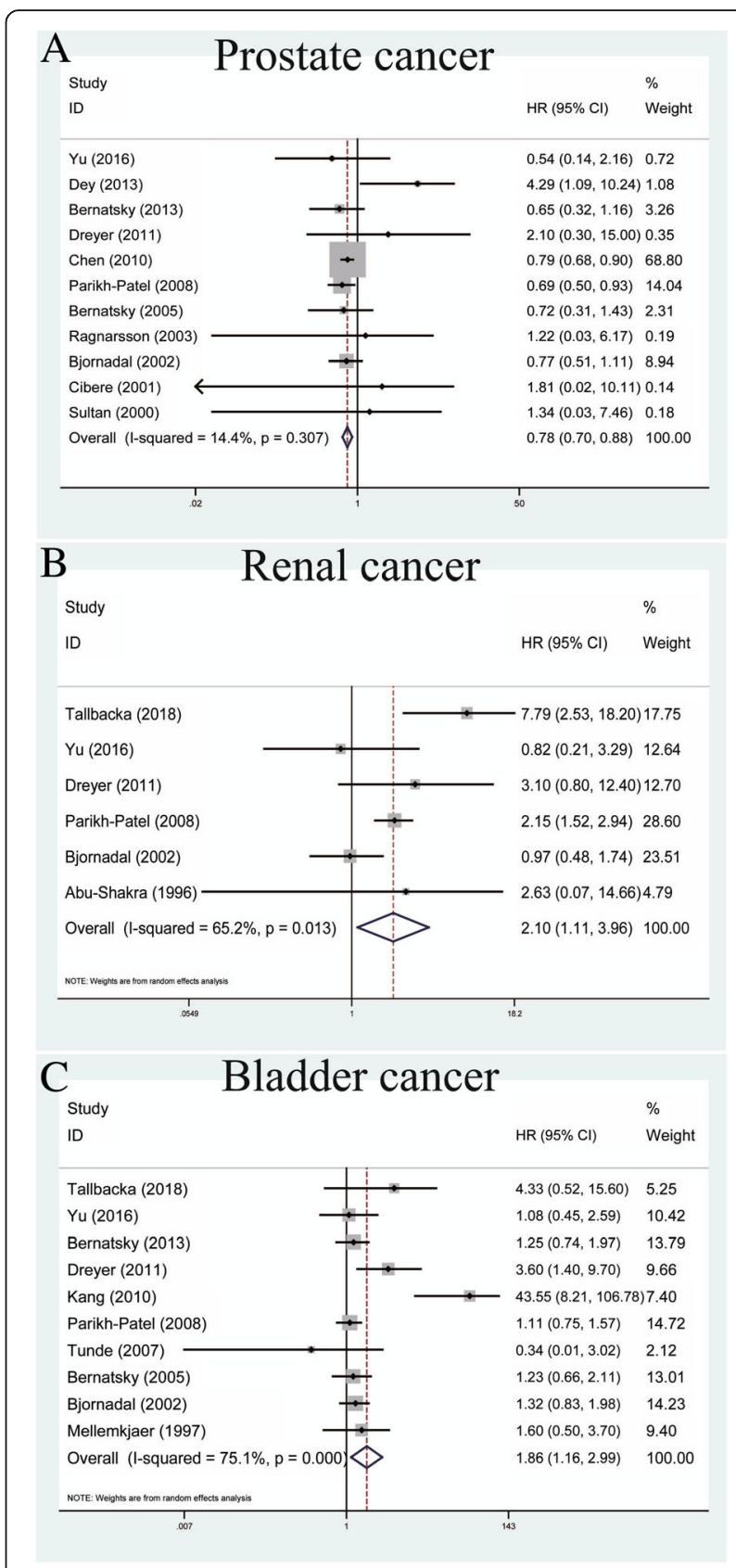

Fig. 4 Forest plots of SLE associated with urinary cancers. a Prostate cancer; $\mathbf{b}$ renal cancer; c bladder cancer 


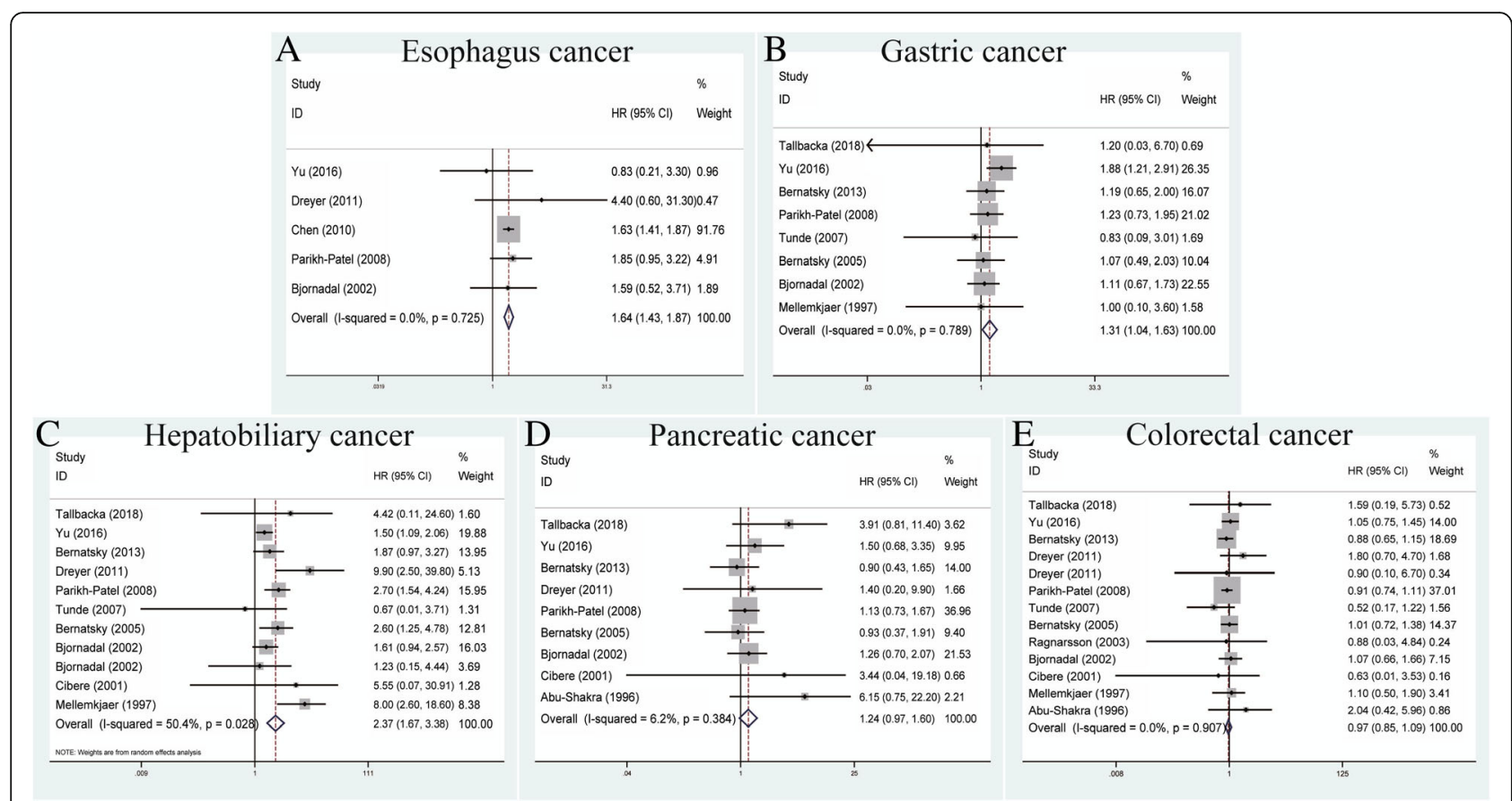

Fig. 5 Forest plots of SLE associated with digestive cancers. a Esophagus cancer; $\mathbf{b}$ gastric cancer; $\mathbf{c}$ hepatobiliary cancer; $\mathbf{d}$ pancreatic cancer; e colorectal cancer

account for the decreased risk of prostate cancer in SLE compared with males without SLE [46]. Moreover, several important co-stimulatory molecules had been demonstrated to play crucial roles in both the pathogenesis of SLE and carcinogenesis, such as OX40L and CTLA4 $[47,48]$. Hence, we hypothesize that testosterone and several co-stimulatory molecules in these two cancers might reverse the oncogenic role of SLE. More attention should be paid to the underlying potential mechanisms between SLE and cancer risk in further studies.

Several potential mechanisms could account for cancer development in SLE patients. These patients, by virtue of their disease, have basic defects in immune cell function, resulting in immune dysregulation which might prevent aberrant cells from being removed and eventually contributing to increased cancer risk [49]. On the other hand, drugs for immunosuppressive therapy could also potentiate immune dysregulation and lead to further increased risks for developing cancer [50]. Other studies also reported the existence of several important co-stimulatory molecules, including OX40L and CTLA4, which could play crucial roles in both the pathogenesis of SLE and carcinogenesis $[47,48]$. Additionally, as a pivotal regulatory element of the immune response magnitude, CTLA4 could be considered as a two-sided knife which predisposes individuals to tumor growth and/or progression under extraordinary expression and accelerates the formation and/or manifestation of inflammatory autoimmune disorders under compromised expression. An association between CTLA4 and SLE not only targets position +49 at the leader peptide but also screens the other single nucleotide polymorphic variants (SNPs) located at the regulatory region and the 3' untranslated region (UTR). However, this hypothesis requires further investigation of the association between the CTLA4 gene at position $+49 \mathrm{~A} / \mathrm{G}$ and SLE because of other relevant studies with inconsistent results.

Several risk factors should also be taken into consideration. Smoking could be regarded as a significant etiologic agent for cancer development in SLE. Compared with those who did not smoke, the lung cancer risk of lupus patients who smoked was found to be increased almost four-fold (adjusted hazard ratio $(\mathrm{HR})=3.6,95 \% \mathrm{CI}=1.32-9.83$ ). This underlined once again the universal importance of smoking cessation, particularly in chronic autoimmune disorders such as SLE [51]. Bernatsky et al. put forward the hypotheses that breast cancer risk in SLE might be influenced by autoantibody profiles or drug exposures, such as nonsteroidal anti-inflammatory drugs and antimalarial drugs, although no definite associations were ultimately revealed [52]. As for the increased incidence rate of non-Hodgkin's lymphoma in patients with SLE, Kang et al. proposed that abnormal B-cell function and the use of immunosuppressive agents might lead to lymphoma by direct mutagenesis or by disturbing immune surveillance [27]; other factors include age, underlying genetic factors, environmental triggers.

Notably, as displayed in Table 1, nine enrolled studies including several of the biggest ones did not report 

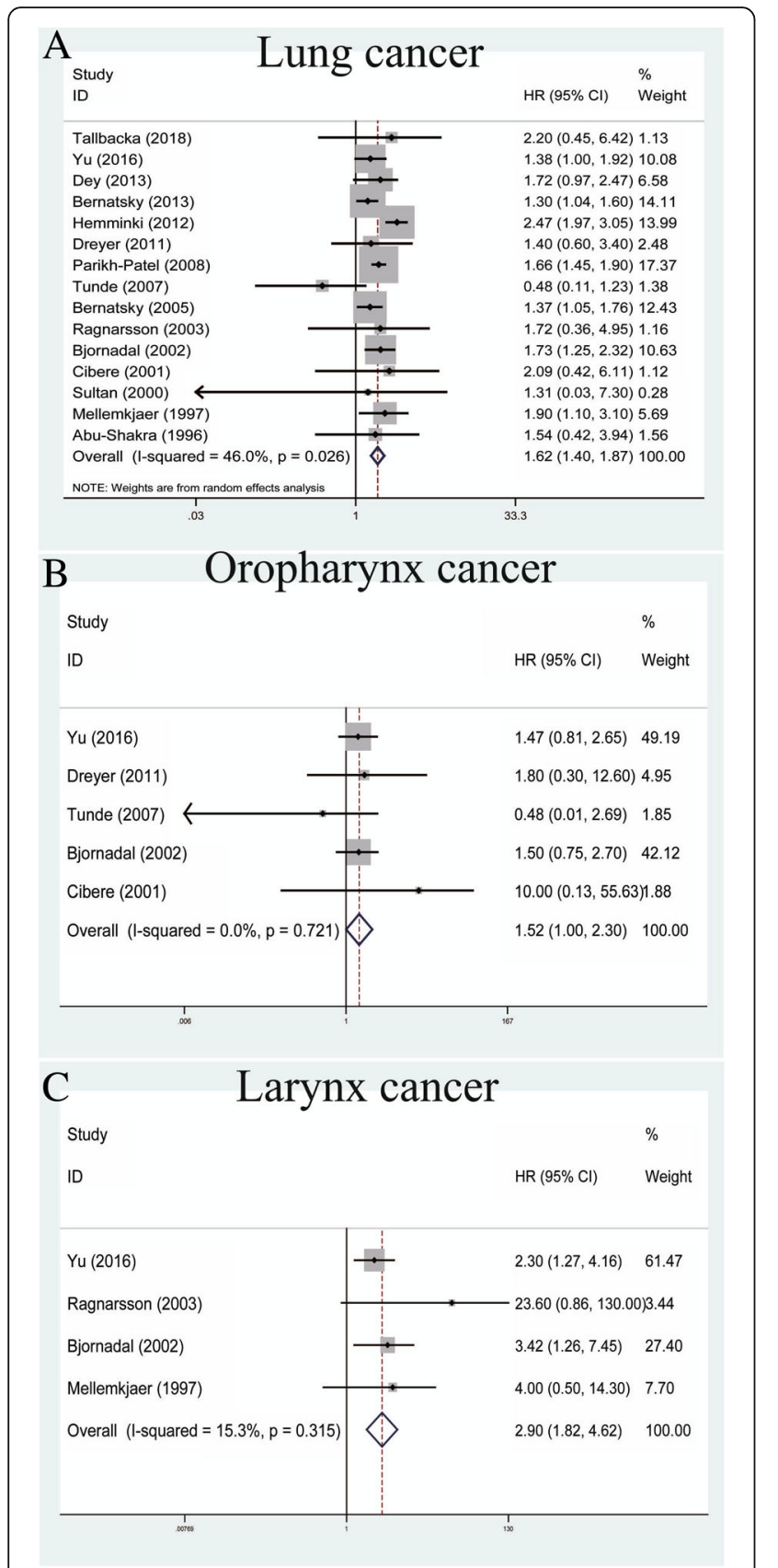

Fig. 6 Forest plots of SLE associated with respiratory cancers. a Lung cancer; b oropharynx cancer; c larynx cancer

diagnostic criteria for SLE. Among these studies, most of them utilized the research databases such as the Center for Primary Health Care Research, the National Health Insurance Claims Database, and Patient Discharge Dataset, which recorded complete data on all discharges with dates of hospitalization and diagnoses, the International Classification of Diseases codes, and so on. Therefore, these studies relied on the diagnosis having been recorded correctly and were easily associated with the selection bias of patient inclusion. Hence, further confirmation on diagnostic criteria were required to minimize these issues. Furthermore, repeated analysis was conducted to include only those papers in which SLE was diagnosed according to accepted criteria. As detailed in Additional file 5: Table S2, most of our results were consistent, except for renal cancer, oropharynx cancer, cutaneous melanoma, and non-melanoma skin cancer. Our re-analysis indicated that no significant associations were revealed between SLE and these four cancers. More relevant studies with larger sample sizes are required to verify our findings. Results from sensitivity analysis and publication bias should also be discussed. The pooled SIRs with 95\% CIs were not significantly influenced by individual studies, suggesting stability of our results (Additional file 3: Figure S2C). For the male category, the study by Chen et al. [15] was found to significantly influence the estimated pooled SIR. Similarly, the $P$ values of Begg's and Egger's test were all above 0.05 , indicating the absence of significant publication bias, except as indicated in Additional file 4: Figure S3E, where a $P$ value for Begg's test was 0.083 and a $P$ value for Egger's test was 0.036, indicating the existence of publication bias. When considering these two aspects, the outcomes should be interpreted with caution.

The strengths of this study were mainly the well-designed methodology of the meta-analysis and the enrollment of all eligible studies, thus providing sufficient statistical power to draw a comprehensive conclusion. Finally, heterogeneity in this study remained low to moderate, even without heterogeneity. Nonetheless, several potential limitations should also be acknowledged. Firstly, the article language was restricted to English, and some relevant articles written in other languages might have been missed. Moreover, although most of our results indicated no significant publication bias, some small negative studies are less likely to be published. Secondly, due to the limited data on this topic, some confounding factors (such as age, sex, and environmental triggers) were not fully clarified, which could result in an inaccurate estimation of their true relationship. Finally, due to insufficient data extracted from primary articles, subgroup analyses were not performed on factors such as ethnicity, alcohol use, and smoking.

\section{Conclusions}

Taken together, our results shed light on SLE being associated with increased risks of overall cancer, females or males suffering from cancers, non-Hodgkin's lymphoma, Hodgkin's lymphoma, leukemia, multiple myeloma, cervix, vagina/vulva, renal, bladder, esophagus, gastric, hepatobiliary, lung, oropharynx, larynx, non-melanoma 




Fig. 7 Forest plots of SLE associated with other cancers. a Cutaneous melanoma; b non-melanoma skin cancer; c brain cancer; $\mathbf{d}$ thyroid cancer

skin, and thyroid cancers, and decreased risks of prostate cancer and cutaneous melanoma. Moreover, no significant associations were revealed between SLE and breast, uterus, ovarian, pancreatic, colorectal, or brain cancers. Despite the aforementioned limitations, these outcomes provide a fairly valid and generalizable description of the occurrence of cancers in SLE. Future high-quality research is required to verify our findings and this should pay more attention to the underlying mechanisms between SLE and cancers risks.

\section{Additional files}

Additional file 1: Figure S1. Flow diagram of the literature selection process. (PDF $353 \mathrm{~kb}$ )

Additional file 2: Table S1. SIRs with $95 \% \mathrm{Cls}$ and Observed/Expected events of individual studies enrolled in this study. (DOCX $37.2 \mathrm{~kb}$ )

Additional file 3: Figure S2. Sensitivity analysis of each included study; (A) The overall cancer; (B) The female group; (C) The male group; (D) NonHodgkin's lymphoma; (E) Hodgkin's lymphoma; (F) Leukemia; (G) Multiple myeloma; (H) Breast cancer; (I) Uterus cancer; (J) Cervix cancer; (K) Ovarian cancer; (L) Vagina/vulva cancer; (M) Prostate cancer; (N) Renal cancer; $(\mathrm{O})$ Bladder cancer; (P) Esophagus cancer; (Q) Gastric cancer; (R) Hepatobiliary cancer; (S) Pancreatic cancer; (T) Colorectal cancer; (U) Lung cancer; (V) Oropharynx cancer; (W) Larynx cancer; (X) Cutaneous melanoma; (Y) Nonmelanoma skin cancer; (Z) Brain cancer; ( $\beta$ ) Thyroid cancer. (PDF 3250 kb)

Additional file 4: Figure S3. Begg's funnel plots of the publication bias; (A) The overall cancer; (B) The female group; (C) The male group; (D) Non-Hodgkin's lymphoma; (E) Hodgkin's lymphoma; (F) Leukemia; (G) Multiple myeloma; (H) Breast cancer; (I) Uterus cancer; (J) Cervix cancer; (K) Ovarian cancer; (L) Vagina/vulva cancer; (M) Prostate cancer; (N) Renal cancer; $(\mathrm{O})$ Bladder cancer; $(\mathrm{P})$ Esophagus cancer; (Q) Gastric cancer; (R) Hepatobiliary cancer; (S) Pancreatic cancer; (T) Colorectal cancer; (U) Lung cancer; (V) Oropharynx cancer; (W) Larynx cancer; $(X)$ Cutaneous melanoma; (Y) Non-melanoma skin cancer; ( $(\mathrm{)})$ Brain cancer; ( $($ ) Thyroid cancer. (PDF $1860 \mathrm{~kb}$ )

Additional file 5: Table S2. Meta-analysis results for included studies diagnosed according to accepted criteria of SLE. (DOCX $2320 \mathrm{~kb}$ )

\section{Abbreviations}

Cl: Confidence interval; MeSH: Medical Subject Headings; NOS: NewcastleOttawa Scale; PRISMA: Preferred Reporting Items for Systematic Reviews and Meta-Analyses; SIR: Standardized incidence rate; SLE: Systemic lupus erythematosus 


\section{Acknowledgements}

We would like to thank the researchers and study participants for their contributions.

\section{Funding}

None declared.

\section{Availability of data and materials}

Data sharing is not applicable to this article as no datasets were generated or analyzed during the current study.

\section{Authors' contributions}

LS wrote the manuscript with significant contributions from all co-authors. YW performed the literature search, data extraction, and quality assessment. JZ and NS performed all statistical analysis. XX and YL conceived of the project and participated in its design and coordination. All authors read and approved the final manuscript.

\section{Ethics approval and consent to participate}

Not applicable.

\section{Consent for publication}

Not applicable.

\section{Competing interests}

The authors declare that they have no competing interests.

\section{Publisher's Note}

Springer Nature remains neutral with regard to jurisdictional claims in published maps and institutional affiliations.

\section{Author details}

'Department of Dermatology, The First Affiliated Hospital of Nanjing Medical University, No. 300 Guangzhou Road, Nanjing 210029, China. ${ }^{2}$ Department of Urology, The First Affiliated Hospital of Nanjing Medical University, No. 300 Guangzhou Road, Nanjing 210029, China.

Received: 15 August 2018 Accepted: 31 October 2018

Published online: 06 December 2018

\section{References}

1. Rahman A, Isenberg DA. Systemic lupus erythematosus. N Engl J Med. 2008; 358(9):929-39.

2. Lawrence RC, Helmick CG, Arnett FC, Deyo RA, Felson DT, Giannini EH, Heyse SP, Hirsch R, Hochberg MC, Hunder GG, et al. Estimates of the prevalence of arthritis and selected musculoskeletal disorders in the United States. Arthritis Rheum. 1998:41(5):778-99.

3. Wang J, Pan HF, Su H, Li XP, Xu JH, Ye DQ. Tuberculosis in systemic lupus erythematosus in Chinese patients. Trop Dr. 2009:39(3):165-7.

4. Alahlafi AM, Wordsworth P, Lakasing L, Davies D, Wojnarowska F. The basement membrane zone in patients with systemic lupus erythematosus: immunofluorescence studies in the skin, kidney and amniochorion. Lupus. 2004;13(8):594-600.

5. Rees F, Doherty M, Grainge MJ, Lanyon P, Zhang W. The worldwide incidence and prevalence of systemic lupus erythematosus: a systematic review of epidemiological studies. Rheumatology (Oxford). 2017;56(11): 1945-61.

6. Choi MY, Flood K, Bernatsky S, Ramsey-Goldman R, Clarke AE: A review on SLE and malignancy. Best Pract Res Clin Rheumatol. 2017;31(3):373-96.

7. Knight JS, Kaplan MJ. Cardiovascular disease in lupus: insights and updates. Curr Opin Rheumatol. 2013;25(5):597-605.

8. Maroz N, Segal MS. Lupus nephritis and end-stage kidney disease. Am J Med Sci. 2013;346(4):319-23.

9. Gayed M, Bernatsky S, Ramsey-Goldman R, Clarke A, Gordon C. Lupus and cancer. Lupus. 2009;18(6):479-85.

10. Zhang M, Li XM, Wang GS, Qian L, Tao JH, Ma Y, Li XP. Thyroid cancer in systemic lupus erythematosus: a meta analysis. Int J Clin Exp Pathol. 2014 7(9):6270-3

11. Yun JS, Bae JM, Kim KJ Jung YS, Kim GM, Kim HR, Lee JS, Ko SH, Cha SA Ahn YB. Increased risk of thyroid diseases in patients with systemic lupus erythematosus: a nationwide population-based study in Korea. PLoS One. 2017:12(6):e0179088

12. Wadstrom H, Arkema EV, Sjowall C, Askling J, Simard JF. Cervical neoplasia in systemic lupus erythematosus: a nationwide study. Rheumatology (Oxford). 2017;56(4):613-9.

13. Azrielant S, Tiosano S, Watad A, Mahroum N, Whitby A, Comaneshter D, Cohen AD, Amital H. Correlation between systemic lupus erythematosus and malignancies: a cross-sectional population-based study. Immunol Res. 2017;65(2):464-9.

14. Tallbacka KR, Pettersson T, Pukkala E. Increased incidence of cancer in systemic lupus erythematosus: a Finnish cohort study with more than 25 years of follow-up. Scand J Rheumatol. 2018;47:1-4. Epub ahead of print.

15. Chen YJ, Chang YT, Wang CB, Wu CY. Malignancy in systemic lupus erythematosus: a nationwide cohort study in Taiwan. Am J Med. 2010; 123(12):1150.e1151-6.

16. Rezaieyazdi Z, Tabaei S, Ravanshad Y, Akhtari J, Mehrad-Majd H. No association between the risk of breast cancer and systemic lupus erythematosus: evidence from a meta-analysis. Clin Rheumatol. 2018;37(6): 1511-9.

17. Moher D, Shamseer L, Clarke M, Ghersi D, Liberati A, Petticrew M, Shekelle P, Stewart LA, Group P-P. Preferred reporting items for systematic review and meta-analysis protocols (PRISMA-P) 2015 statement. Syst Rev. 2015;4:1.

18. Stang A. Critical evaluation of the Newcastle-Ottawa scale for the assessment of the quality of nonrandomized studies in meta-analyses. Eur J Epidemiol. 2010;25(9):603-5.

19. DerSimonian R, Kacker R. Random-effects model for meta-analysis of clinical trials: an update. Contemp Clin Trials. 2007;28(2):105-14.

20. Egger M, Davey SG, Schneider M, Minder C. Bias in meta-analysis detected by a simple, graphical test. BMJ. 1997;315(7129):629-34.

21. Yu KH, Kuo CF, Huang LH, Huang WK, See LC. Cancer risk in patients with inflammatory systemic autoimmune rheumatic diseases: a nationwide population-based dynamic cohort study in Taiwan. Medicine. 2016;95(18):e3540.

22. Khaliq W, Qayyum R, Clough J, Vaidya D, Wolff AC, Becker DM. Comparison of breast cancer risk in women with and without systemic lupus erythematosus in a Medicare population. Breast Cancer Res Treat. 2015; 151(2):465-74

23. Dey D, Kenu E, Isenberg DA. Cancer complicating systemic lupus erythematosus - a dichotomy emerging from a nested case-control study. Lupus. 2013;22(9):919-27.

24. Bernatsky S, Ramsey-Goldman R, Labrecque J, Joseph L, Boivin JF, Petri M, Zoma A, Manzi S, Urowitz MB, Gladman D, et al. Cancer risk in systemic lupus: an updated international multi-centre cohort study. J Autoimmun. 2013:42:130-5.

25. Hemminki K, Liu X, Ji J, Sundquist J, Sundquist K. Effect of autoimmune diseases on risk and survival in histology-specific lung cancer. Eur Respir J. 2012:40(6):1489-95.

26. Dreyer L, Faurschou M, Mogensen M, Jacobsen S. High incidence of potentially virus-induced malignancies in systemic lupus erythematosus: a long-term followup study in a Danish cohort. Arthritis Rheum. 2011; 63(10):3032-7.

27. Kang KY, Kim HO, Yoon HS, Lee J, Lee WC, Ko HJ, Ju JH, Cho CS, Kim HY, Park SH. Incidence of cancer among female patients with systemic lupus erythematosus in Korea. Clin Rheumatol. 2010;29(4):381-8.

28. Gadalla SM, Amr S, Langenberg P, Baumgarten M, Davidson WF, Schairer C, Engels EA, Pfeiffer RM, Goedert JJ. Breast cancer risk in elderly women with systemic autoimmune rheumatic diseases: a population-based case-control study. Br J Cancer. 2009;100(5):817-21.

29. Parikh-Patel A, White $\mathrm{RH}$, Allen M, Cress R. Cancer risk in a cohort of patients with systemic lupus erythematosus (SLE) in California. Cancer Causes Control. 2008;19(8):887-94.

30. Tarr T, Gyorfy B, Szekanecz E, Bhattoa HP, Zeher M, Szegedi G, Kiss E. Occurrence of malignancies in Hungarian patients with systemic lupus erythematosus: results from a single center. Ann N Y Acad Sci. 2007; 1108:76-82

31. Bernatsky S, Boivin JF, Joseph L, Rajan R, Zoma A, Manzi S, Ginzler E, Urowitz M, Gladman D, Fortin PR, et al. An international cohort study of cancer in systemic lupus erythematosus. Arthritis Rheum. 2005;52(5):1481-90.

32. Ragnarsson $\mathrm{O}$, Grondal G, Steinsson K. Risk of malignancy in an unselected cohort of Icelandic patients with systemic lupus erythematosus. Lupus. 2003;12(9):687-91. 
33. Bjornadal L, Lofstrom B, Yin L, Lundberg IE, Ekbom A. Increased cancer incidence in a Swedish cohort of patients with systemic lupus erythematosus. Scand J Rheumatol. 2002;31(2):66-71.

34. Cibere J, Sibley J, Haga M. Systemic lupus erythematosus and the risk of malignancy. Lupus. 2001;10(6):394-400.

35. Sultan SM, loannou Y, Isenberg DA. Is there an association of malignancy with systemic lupus erythematosus? An analysis of 276 patients under longterm review. Rheumatology (Oxford). 2000;39(10):1147-52.

36. Ramsey-Goldman R, Mattai SA, Schilling E, Chiu YL, Alo CJ, Howe HL, Manzi $\mathrm{S}$. Increased risk of malignancy in patients with systemic lupus erythematosus. J Invest Med. 1998;46(5):217-22.

37. Mellemkjaer L, Andersen V, Linet MS, Gridley G, Hoover R, Olsen JH. NonHodgkin's lymphoma and other cancers among a cohort of patients with systemic lupus erythematosus. Arthritis Rheum. 1997;40(4):761-8.

38. Abu-Shakra M, Gladman DD, Urowitz MB. Malignancy in systemic lupus erythematosus. Arthritis Rheum. 1996;39(6):1050-4.

39. Sweeney DM, Manzi S, Janosky J, Selvaggi KJ, Ferri W, Medsger TA Jr, Ramsey-Goldman R. Risk of malignancy in women with systemic lupus erythematosus. J Rheumatol. 1995;22(8):1478-82

40. Pettersson T, Pukkala E, Teppo L, Friman C. Increased risk of cancer in patients with systemic lupus erythematosus. Ann Rheum Dis. 1992;51(4):437-9.

41. Ni J, Qiu L, Hu LF, Cen H, Zhang M, Wen PF, Wang XS, Pan HF, Ye DQ. Lung, liver, prostate, bladder malignancies risk in systemic lupus erythematosus: evidence from a meta-analysis. Lupus. 2014;23(3):284-92.

42. Bernatsky S, Ramsey-Goldman R, Foulkes WD, Gordon C, Clarke AE. Breast, ovarian, and endometrial malignancies in systemic lupus erythematosus: a meta-analysis. Br J Cancer. 2011;104(9):1478-81.

43. Huang HB, Jiang SC, Han J, Cheng QS, Dong CB, Pan CM. A systematic review of the epidemiological literature on the risk of urological cancers in systemic lupus erythematosus. J Cancer Res Clin Oncol. 2014;140(7):1067-73.

44. Hoene KA, Kaufman MR, Cates JM, Chang SS. Inflammatory myofibroblastic tumor of the urinary bladder in a 27-year-old woman with systemic lupus erythematosus. Int J Urol. 2008;15(2):182-4.

45. Plotz PH, Klippel JH, Decker JL, Grauman D, Wolff B, Brown BC, Rutt G. Bladder complications in patients receiving cyclophosphamide for systemic lupus erythematosus or rheumatoid arthritis. Ann Intern Med. 1979;91(2):221-3.

46. Mok CC, Lau CS. Profile of sex hormones in male patients with systemic lupus erythematosus. Lupus. 2000;9(4):252-7.

47. Wang L, Li D, Fu Z, Li H, Wei J, Li D. Association of CTLA-4 gene polymorphisms with sporadic breast cancer in Chinese Han population. BMC Cancer. 2007;7(1):1-7.

48. Ghaderi A. CTLA4 gene variants in autoimmunity and cancer: a comparative review. Iranian J Immunol. 2011;8(3):127.

49. Kinlen LJ. Malignancy in autoimmune diseases. J Autoimmun. 1992;5(Suppl A):363-71.

50. Chun BC, Bae SC. Mortality and cancer incidence in Korean patients with systemic lupus erythematosus: results from the Hanyang lupus cohort in Seoul, Korea. Lupus. 2005;14(8):635-8.

51. Wu Y, Hou Q. Systemic lupus erythematous increased lung cancer risk: evidence from a meta-analysis. J Cancer Res Ther. 2016;12(2):721-4.

52. Bernatsky S, Ramsey-Goldman R, Petri M, Urowitz MB, Gladman DD, Fortin PF, Ginzler E, Romero-Diaz J, Peschken C, Jacobsen S, et al. Breast cancer in systemic lupus. Lupus. 2017;26(3):311-5.

Ready to submit your research? Choose BMC and benefit from:

- fast, convenient online submission

- thorough peer review by experienced researchers in your field

- rapid publication on acceptance

- support for research data, including large and complex data types

- gold Open Access which fosters wider collaboration and increased citations

- maximum visibility for your research: over $100 \mathrm{M}$ website views per year

At $\mathrm{BMC}$, research is always in progress.

Learn more biomedcentral.com/submissions 